\title{
Exploring Teachers' Motivation for Implementing Cooperative Learning Using Expectancy-Value Theory
}

\author{
Yung-Ho Huang \\ National Taipei University of Education, Taiwan
}

\begin{abstract}
This study investigated junior high school teachers' motivation for implementing cooperative learning $(C L)$ using expectancy-value theory. The subjects were 1864 teachers stratified sampling from public junior high schools in Taiwan. The results of the data analysis indicates: (1) $57 \%$ of teachers reported that CL was "not at all" or "slightly" part of their classroom routines, $20.8 \%$ reported "somewhat", and $22.2 \%$ responded "largely" or "entirely"; (2) the average scores of the all sample teachers were about upper-middle degree in the aspects of "valence" and "teaching loading", about middle degree in the aspects of "expecting success", "expecting failure", and "communicating loading"; (3) cluster analysis divided the all teachers into three groups, they were "high-valence and highexpectancy", "high-valence and high-cost", and "unconcern"; (4) the teacher motivation equation was " $C L$ implementation $=0.234 \times$ expecting success $-0.194 \times$ teaching loading $+0.139 \times$ valence -0.141 x expecting failure".
\end{abstract}

\section{Introduction}

Cooperative learning is a learner-centered instructional strategy in which a small group of students work together to maximize their own and other members' learning. It has been identified as a powerful teaching strategy to raise all students' academic achievements, social competence, and psychological health. It can enhance thinking skills, increase higher-order learning, and improve interpersonal relations and collaborative abilities [1]. Now, cooperative learning is still an effective tool for training students to meet the challenges of 21st century, such as global interdependence, increasing number of democracies, need for creative entrepreneurs, and changes in interpersonal relationships [2].

In Taiwan, "chalk and talk" was the most common method of teaching in schools. In order to change the way teachers teach, and to cultivate students 21st century skills, Taiwan's Ministry of Education has sponsored a project to promote over 800 junior high schools to implement cooperative learning (CL) in classrooms since 2012. One year after starting the project, more and more teachers had used CL in their classrooms, but there are still many teachers who haven't had motivation to use it.

The objectives of this study were:

(1) to find out the frequency that Taiwan's teachers were using $\mathrm{CL}$ in classrooms;

(2) to investigate motivational level of teachers implementing CL;

(3) to classify teachers' motivation into clusters;

(4) to find an regression equation to describe the statistical relationship between teachers motivation and implementation of CL.

\section{Literature Review}

\subsection{Benefits and challenges of CL}

Effective CL must include five elements: positive interdependence, face-to-face promotive interaction, individual and group accountability, social skills, and group processing. These five fundamental elements distinguish CL from other form of group learning. There are many advantages to implement CL. The advantages include having a positive effect on student learning, meeting the needs of more students, improving the interpersonal and collaboration skills, and creating greater levels of engagement [3].

But there are also many challenges with the implementation of CL. First, CL requires careful preparation and implementation in order to ensure that the key elements for successful group work are established. Second, it can be difficult to group students to work well together. Third, group tasks need to be designed so that they lead to high quality group interaction and collaborative learning. Fourth, teachers need to invest in teaching students the interpersonal and small-group skills so that students can work in groups, give more detailed explanations and assistance to each other, and obtained higher learning outcomes. Fifth, some teachers report that they have difficulties with assessing students' group work. Considering the benefits and challenges of CL, while some teachers have the comment that it should be used more widely, others indicate it is a challenge and require commitment on the part of the teacher if it was to be implemented effectively [4]. The challenge may become the major factors that many teachers lack motivation to embrace cooperative learning. 


\subsection{Teacher motivation}

Many factors contribute to the successful implementation of instructional innovation. But research suggests that teachers often play a central role. Therefore, education researchers and school leaders have to concern teachers' motivation of implementing instructional innovation. Motivation is a construct used to explain the initiation, direction, and persistence of behavior, especially goal-directed behavior. In the context of instructional innovation, the concept of teacher motivation is used to explain the degree to which teachers invest attention and effort in initiation, direction, and persistence of the pedagogical processes.

Within the field of teacher motivation, Richardson and Watt [5] propose that the expectancy-value theory is a theoretically comprehensive and empirically robust framework, and it can advance to provide a coherent and integrated model to guide systematic inquiry into teacher motivations. According to Eccles et al. [6] expectancy-value model, task choices are assumed to be influenced by both negative and positive task characteristics, and all choices are assumed to have costs associated with them precisely. Consequently, the relative value and probability of success of various options are key determinants of choice. That can be written with a multiplicative formula: motivation $=$ Expectancy $\mathrm{x}$ value. Expectancies for success is individuals' beliefs about how well they will do on upcoming tasks, either in the immediate or longer term future. Task value is comprised of attainment value, intrinsic value, utility value, and cost. Attainment value is the personal importance of doing well on the task. Intrinsic value is the enjoyment the individual gets from performing the task. Utility value is determined by how well a task relates to current and future goals. Cost is the negative aspects of engaging in the task, such as performance anxiety, the amount of effort, and the lost opportunities et al.

Abrami, Poulsen and Chambers [7] applied the expectancy-value model to investigate the motivation differences between users and non-users of cooperative learning. They developed a questionnaire called "The Cooperative Learning Implementation Questionnaire" that contained 48 items grouped under three broad categories, namely: perceived value of the innovation, expectancy of success, and perceived cost. The result indicated that expectancy of success appeared to be most important in differentiating $\mathrm{CL}$ users from non-users. The teacher motivation equation could be expressed as: $(0.44 \mathrm{x}$ expectancy $)+(0.04 \mathrm{x}$ value $)-(0.01 \mathrm{x}$ cost $)=$ use of cooperative learning

\section{Methodology}

\subsection{Participants}

The population of the study included the all junior high school teachers in Taiwan. A random sample of 209 schools was taken for the purpose of research. The scale was distributed to the 209 schools and then randomly distributed to 10 teachers at each school during the period from Oct 2013 to May 2014. The number of scale sent out was 2090, and the number returned was 1864 (an $89.19 \%$ return rate).

\subsection{Instrument development}

On the basis of expectancy-value theory, the work of Abrami et al. [7], and educational context of Taiwan, an instrument that was called Cooperative Learning Motivation Scale (CLMS) was brought out. A Principal Axis Factor with a Varimax rotation of the 34 5-point Likert scale (1 = strongly disagree to 5 $=$ strongly agree) questions from this motivation scale was conducted on data gathered from 234 participants. This analysis yielded a five-factor solution with a simple structure, and explained $62.69 \%$ of the variance (factor loadings $=>.49$ ). These five factor were labeled "valence" (e.g., "CL fits in with my instructional needs."), "expecting success" (e.g., "I can implement CL successfully in my classroom."), "expecting failure" (e.g., "If I use CL, my students can't learn effectively."), "communicating loading" (e.g., "If I use CL, I will have to spend a lot of time to communicate to parents. ") and "teaching loading" (e.g., "If I use CL, I will have to spend a lot of time to prepare my lesson.").

The valence subscale consisted of 10 items $(\alpha=$ .91 ), the expecting success subscale consisted of 10 items $(\alpha=.93)$, the expecting failure subscale consisted of 5 items $(\alpha=.82)$, the communicating loading subscale consisted of 3 items $(\alpha=.99)$, and the teaching loading subscale consisted of 6 items ( $\alpha$ $=.87$ ). The whole motivation scale was found to be highly reliable (34 items; $\alpha=.85$ ).

\section{Results and Discussion}

\subsection{Frequency of CL implementation}

Table 1 shows $22.1 \%$ of teachers reported that CL was "not at all" part of their classroom routines, $34.9 \%$ reported "slightly", 20.8\% reported "somewhat", $11.0 \%$ reported "largely", and 11.2\% reported "entirely". In other words, over half of teachers $(57.0 \%)$ were low-frequency CL users, and only about one-fifth of teachers $(22.2 \%)$ were highfrequency users. 
Table 1. Frequency of CL implementation

\begin{tabular}{lcc}
\hline \multicolumn{1}{c}{ Frequency } & Number & Percentage \\
\hline Not at all & 406 & 22.1 \\
Slightly & 641 & 34.9 \\
Somewhat & 382 & 20.8 \\
Largely & 201 & 11.0 \\
Entirely & 205 & 11.2 \\
\hline
\end{tabular}

\subsection{Motivational level}

Table 2 shows the average score of the all sample teachers was 37.13 on the factor "valence", 34.28 on "expecting success", 14.17 on "expecting failure", 20.82 on "teaching loading", and 9.17 on "communicating loading". Their average scores of items were respectively $3.71,3.43,2.83,3.47$, and 3.06. Namely, teachers were about upper-middle degree in the aspects of "valence" and "teaching loading", about middle degree in the aspects of "expecting success", "expecting failure", and "communicating loading".

Table 2. Mean and SD of teachers' motivation

\begin{tabular}{lcccc}
\hline \multicolumn{1}{c}{ Factor } & Mean & SD & Items & Mean/Items \\
\hline Valence & 37.13 & 5.98 & 10 & 3.71 \\
Expecting success & 34.28 & 6.10 & 10 & 3.43 \\
Expecting failure & 14.17 & 3.70 & 5 & 2.83 \\
Teaching loading & 20.82 & 4.38 & 6 & 3.47 \\
Comm. loading & 9.17 & 2.26 & 3 & 3.06 \\
\hline
\end{tabular}

\subsection{Clusters of teachers' motivation}

Table 3 shows that the k-means clustering divided the all teachers into three groups. The first group was named "high-valence and high-expectancy" that in which teachers have high level of valence and expecting success $(\mathrm{N}=634)$. The second group was named "high-valence and high-cost" that included teachers with relatively high levels of valence, expecting success, Teaching loading, and Communicating loading $(\mathrm{N}=628)$. The third group was named "unconcern" as the profile was characterized by without any obvious high or low response on all factors $(\mathrm{N}=602)$.

Table 4 shows that the one-way ANOVA with the $\mathrm{CL}$ implementation frequency as the dependent variable was significant, $\mathrm{F}(2,2832)=170.01, \mathrm{p}<$ .001 , and post hoc pairwise comparisons of the estimated marginal means indicated that all groups differed on CL implementation frequency.

\subsection{Prediction of $C L$ implementation}

The five factors of motivation were used to predict the CL implementation. To estimate the level of predication, a multiple regression was conducted using the five factors as independent variables and teacher's frequency of CL implementation as the dependent variable. The results in the multiple regression analysis output indicated that only four factors were statistically significant to predict the dependent variable (see table 5). The multiple correlation coefficient $\mathrm{R}$ was .511 and that the four predictors were able to explain together $26.1 \%$ of the variance in teacher's frequency of CL implementation. The best predictor was Expecting Success, then Teaching Loading, then Valence, and the least one was Expecting Failure. The regression analysis generated an equation to describe the statistical relationship between teacher motivation and implementation of CL: Frequency of CL implementation $=0.234 \times$ expecting success -0.194 $\times$ teaching loading $+0.139 \times$ valence $-0.141 \times$ expecting failure.

Table 3. Cluster analysis results

\begin{tabular}{|c|c|c|c|c|}
\hline \multirow{2}{*}{ Factor } & \multicolumn{3}{|c|}{ Cluster } & \multirow{2}{*}{$\mathrm{F}$} \\
\hline & 1 & 2 & 3 & \\
\hline Valence & 4.06 & 3.79 & 3.27 & $391.04 * * *$ \\
\hline $\begin{array}{l}\text { Expecting } \\
\text { success }\end{array}$ & 3.85 & 3.50 & 2.91 & $606.73 * * *$ \\
\hline $\begin{array}{l}\text { Expecting } \\
\text { failure }\end{array}$ & 2.15 & 3.13 & 3.24 & $726.57 * * *$ \\
\hline $\begin{array}{l}\text { Teaching } \\
\text { loading }\end{array}$ & 2.91 & 4.03 & 3.47 & $624.19 * * *$ \\
\hline $\begin{array}{l}\text { Communicating } \\
\text { loading }\end{array}$ & 2.67 & 3.72 & 2.77 & $619.11 * * *$ \\
\hline $\mathrm{N}$ & 634 & 628 & 602 & \\
\hline
\end{tabular}

Table 4. M \& SD on CL implementation by groups

\begin{tabular}{lccc}
\hline \multicolumn{1}{c}{ Group } & M & SD & F \\
\hline $\begin{array}{l}\text { high-valence and } \\
\text { high-expectancy } \\
\text { high-valence and }\end{array}$ & 3.22 & 1.30 & \\
$\begin{array}{l}\text { high-cost } \\
\text { Unconcern }\end{array}$ & 2.32 & 1.13 & $170.01 * * *$ \\
\hline
\end{tabular}

Table 5. Multiple regressing coefficients for motivation predicting implementation

\begin{tabular}{lccc}
\hline \multicolumn{1}{c}{ Variable } & $\mathrm{R}$ & $\mathrm{B}$ & Beta \\
\hline ( Constant ) & & 17.734 & \\
Expecting success & .408 & 1.006 & .234 \\
Teaching loading & .481 & -1.159 & -.194 \\
Valence & .499 & .612 & .139 \\
Expecting failure & .511 & -1.000 & -.141 \\
\hline
\end{tabular}

\subsection{Discussion of findings}

Cooperative learning which is one of the most successful innovative methods in the last decades is a typical learner-centered instructional strategy. In 
order to transform classroom pedagogy, it is important for teacher educators, school administrators, and researchers to help teacher adopt cooperative learning, and understand teachers' motivation to implement it in their classrooms. This section discusses the implications of the results for instructional innovation.

1. Comparing to the findings of Bassett, McWhirter and Kitzmiller [8] that about $16 \%$ of America's teachers were considered low users, about $43 \%$ were moderate users, and about $41 \%$ were considered high users, CL was not so common in Taiwan's classroom that $57 \%$ of Taiwan's teachers were low users, and about $22.2 \%$ were high users. The reasons that Taiwan's teachers had lower using rate maybe come from the difference of teachers' motivation, culture and educational institution between the two countries. For cooperative learning to work more commonly in Taiwan's classroom, reformers need to consider the important of teachers' motivation, culture and educational institution.

2. The benefits of CL were well supported by theory and classroom research, but the strategy was still not so common in Taiwan's classrooms. This study found that the average CL valence of Taiwan's teachers was about upper-middle degree that might not be enough for teacher to initiate and direct their action to implement CL. That showed the benefits of CL were not accepted fully by most of teachers. Lupme, Czerniak and Haney [9] indicated teachers' value beliefs about using cooperative learning might play an important role in its ultimate implementation. In order for teachers to understand the value of CL, professional development providers should afford teachers the opportunity to identify their CL beliefs, reflect on the current status of the responsiveness of their students leaning, and create a dialogue with administrators and CL experts about these issues.

3. The result of this study showed that increasing teaching loading was the most negative and influential factor of teacher motivation (average score of items was 3.47). This meant that teachers were worried that CL would cost them a lot of time or effort to carry out, especially for those teachers acquired the habit of lecture from traditional teaching culture. When they try to use CL in their classroom, they have to spend time retooling their teaching methods and revising their teaching materials. Gillies and Boyle [10] indicated when teachers choose to use CL, they need to determine the class organization, the type of task, the patterns of communication, and the types of academic and social behaviors expected from the students. It is not surprising that teachers may feel challenged by the sheer complexity of CL. But this does not mean that teachers should desist from trying. Actually, it raises issues about the importance of providing teachers with opportunities for ongoing professional development in the application of $\mathrm{CL}$ in their classrooms. Besides, working with colleagues, such as in professional learning communities, to co-plan, develop teaching skills, and problem-solve would make the transition to cooperative learning easier.

4. The equation of predicting CL implementation showed expectancy of success was the most impactful predictor. Expecting success contributed $16.6 \%$ toward the explained variance in the model. The research of Abrami et al. [7] also showed expectancy of success appeared to be most important in differentiating CL users from non-users. Although high level of CL valence is important, but its impact on CL implementing is less than expectancy beliefs. Besides, even though teachers always complain that using CL will increase their communicating loading (for example, CL costs them a lot of time to communicate to parents), the factor was not a significant predictor of CL implementation.

This study showed expectancy of success is a critical ingredient of motivation. Without believing in our ability to develop and implement CL that can address the instructional challenges, we will not even act. In order to promote more teachers using this instructional innovation, professional developers should pay more attention on teachers' expectancy beliefs about CL.

\section{Conclusion}

1. After the first year of starting CL promoting project, most of junior high teachers in Taiwan were still low-frequency CL users, and only about onefifth of teachers were high-frequency users. The educational reformers need to consider the important of teachers' motivation, culture and educational institution.

2. The teachers' motivation were about uppermiddle degree in the aspects of "valence" and "teaching loading", about middle degree in the aspects of "expecting success", "expecting failure", and "communicating loading". It's important to provide teachers with ongoing professional development in the application of CL.

3. The all teachers could be divided into "highvalence and high-expectancy", "high-valence and high-cost", and "unconcern" groups.

4. The teacher motivation equation was " $\mathrm{CL}$ implementation $=0.234 \times$ expecting success -0.194

$\times$ teaching loading $+0.139 \times$ valence $-0.141 \times$ expecting failure". Expecting success contributed the most to the explained variance in the model. In order to promote more teachers using this instructional innovation, professional developers should pay more effort to improve teachers' expectancy beliefs about CL. 


\section{References}

[1] Slavin, R. E. (2010). Co-operative learning: What makes group-work work? In H. Dumont, D. Istance \& F. Benavides (Eds.), The nature of learning: Using research to inspire practice. Paris, France: Organisation for Economic Co-operation and Development.

[2] Johnson, D. W., \& Johnson, R. T. (2014). Cooperative Learning in 21st Century. Anales de Psicología, 30(3), 841-851.

[3] Shindler, J. (2010). Transformative classroom management: Positive strategies to engage all students and promote a psychology of success. San Francisco, CA: Jossey-Bass.

[4] Gillies, R. M., \& Boyle, M. (2010). Teachers' reflections on cooperative learning: Issues of implementation. Teaching and Teacher Education, 26, 933-940.

[5] Richardson, P. W., \& Watt, H. M. G. (2014). Why people choose teaching as a career: An expectancy-value approach to understanding teacher motivation. In P. W. Richadson, S. A. Karabenick \& H. M. G. Watt (Eds.), Teacher motivation: Theory and practice (pp. 3-19). New York, NY: Routledge.

[6] Eccles, J. S., \& Wigfield, A. (2002). Motivational beliefs, values, and goals. Annual Review of Psychology, 53, 109-132.

[7] Abrami, P. C., Poulsen, C., \& Chambers, B. (2004). Teacher motivation to implement an educational innovation: Factors differentiating users and non-users of cooperative learning. Educational Psychology, 24(2), 201-216.

[8] Bassett, C., McWhirter, J. J., \& Kitzmiller, K. (1999). Teacher implementation of cooperative learning groups. Contemporary Education, 71(1), 46-50.

[9] Lupme, A. T., Czerniak, C. M., \& Haney, J. J. (1998). Science teacher beliefs and intentions regarding the use of cooperative learning. School Science and Mathematics, 98(3), 123-132.

[10] Gillies, R. M., \& Boyle, M. (2010). Teachers' reflections on cooperative learning: Issues of implementation. Teaching and Teacher Education, 26, 933-940. 